\title{
What are the Relationships between Teachers' Engagement with Management Information Systems and Their Sense of Accountability?
}

\author{
Uri Perelman \\ Institute of Education, University of London, UK
}

\section{Uri1perelman@gmail.com}

\begin{abstract}
Many public and private sector organizations are supported by Management Information Systems (MIS) for collection, management, analysis, and distribution of the data needed for effective decision-making and enhanced organizational management. The existing body of research on MIS in education focuses on the systems' contribution to achieving organizational objectives and improving managerial practices. So far, research has given little attention to the multifaceted contexts of the technology integration and the effects of MIS on teachers. This study took a critical approach and suggests a linkage between MIS and the global neoliberal discourse, which seeks to implement norms of accountability in educational organizations. In order to examine this supposition, a research question was formed: what are the reciprocal relationships between teachers' engagement with MIS and their sense of accountability? Taking place in an Israeli secondary school, teachers were asked about their perceptions of MASHOV, an Israeli-developed MIS. Teachers exhibited different and often contradictory opinions about MASHOV's usability and its influence on their authenticity and sense of accountability. While management staff and a minority of teachers embraced the changes imposed by MASHOV, other teachers felt that the requirement to continually report through MASHOV left them feeling disempowered and unprofessional.
\end{abstract}

Keywords: Management Information Systems (MIS), Accountability, Transparency, Neoliberalism.

\section{Introduction}

Material published as part of this publication, either on-line or in print, is copyrighted by the Informing Science Institute. Permission to make digital or paper copy of part or all of these works for personal or classroom use is granted without fee provided that the copies are not made or distributed for profit or commercial advantage AND that copies 1) bear this notice in full and 2) give the full citation on the first page. It is permissible to abstract these works so long as credit is given. To copy in all other cases or to republish or to post on a server or to redistribute to lists requires specific permission and payment of a fee. Contact Publisher@InformingScience.org to request redistribution permission.
The following study focuses on the implementation and use of Management Information Systems (MIS) in schools. Originally used in the corporate world, MIS provide vital information and analytical tools that are essential for an efficient and effective management of schools. Several writers have celebrated the ways in which MIS successfully provide schools with organizational and pedagogical enhancements (Blau \&

Editor: Janice Whatley

An earlier, shorter version of this paper was presented at the Chais conference 2014, in Raanana, Israel, and included in Y. Eshet-Alkalai, A. Caspi, N. Geri, Y. Kalman, V. Silber-Varod, \& Y. Yair (Eds.), Proceedings of the Chais Conference for the Study of Innovation and Learning Technologies 2014: Learning in the Technological Era. Raanana: The Open University of Israel. 
Feldman, 2012; Telem, 1995; Visscher, Wild, \& Fung, 2001). However, so far there has been little discussion about the effects that MIS have on their users. Within this limited body of research, studies have mostly focused on the perspectives of head teachers (Blau \& Presser, 2013; Haughey, 2003; Selwood \& Drenoyianni, 1997). Nevertheless, far too little attention has been given to the perspectives of teachers, who represent the majority of the MIS user base.

This study takes the social construction of technology approach (SCOT) to suggest that technology is a manifestation of the social realm, and thus it bears different and even contradicting interpretations by players of potential interest. In the light of this approach, a critical discussion of MIS will be conducted by considering the perspectives and interpretations of teachers concerning the nature of MIS. As the literature review will suggest, the implementation and use of MIS in schools are associated with neoliberal policies, which aim to transform schools into 'businesslike' organizations that abide by principles of accountability. The major objective of the study is to investigate the relationships between teachers' engagement with MIS and their sense of accountability.

\section{Literature Review}

As a matter of public interest, schools regularly find themselves the focus of numerous reforms, aimed at making education more relevant and consistent with the world outside. Moreover, as public institutes that rely on taxpayers' money, schools are under continuous scrutiny to perform efficiently and effectively. In the past, efficiency and effectiveness in education were measured by the schools' abilities to produce knowledgeable and moral students, able to successfully participate in and contribute to society. Today, however, schools are faced with different expectations that seek to equip education with 'business- like' terminology, comprising of 'three interrelated policy technologies; the market, managerialism and performativity' (Ball, 2003, p. 215). This neoliberal discourse views schools as service providers, students as consumers, and education as the offered service.

A common thread among studies that describe the effects of implementing neoliberal practices in schools is the growth in performance data (Ball, 2003; Perry \& McWilliam, 2007; Perryman, 2006). As Ozga (2009) writes:

'Data grew in significance from the late 1970s and expression of anxiety about standards and underperformance, linked to attempts to promote 'good practice', through the 1980s and the rapid buildup of quality assurance processes that required specific data to be produced.' (p.153)

Today, schools require solutions for relieving data-handling pressures, ensuring that decisions are based on credible data, and guaranteeing that records are transmitted objectively and transparently. Originating in the corporate world and linked to 'data-obsessed' neoliberalism, MIS are a prominent digital technology that has continuously developed in the backdrop of neoliberal educational reforms. Broadly speaking, as neoliberalism wishes to eliminate inefficient forms of bureaucracy by advocating the notion of decentralization; schools are held accountable for their own performance and required to collect and publish performance data for the purpose of justifying public expenditures. As demands for accountability increase, so does the 'pressure to perform efficiently and profitably' (Selwyn, 2011a, p. 93); schools must 'provide an account of all school policies and practices to anyone and everyone' (Perry \& McWilliam, 2007, p. 32). In order to ensure that performance data is managed efficiently for maintaining public transparency, schools are instructed to utilize digital technology tools, such as MIS. Although MIS is marketed to schools as a solution for enhancing their data management capabilities, the following study suggests that MIS implementation entails a hidden agenda for establishing a discourse of accountability in schools. As MIS are 'based around activities of reporting, measuring, monitoring, as- 
sessing and accounting' (Griffith \& Andre-Bechely, 2008, in Selwyn, 2011a, p. 91), they help deploy the neoliberal values of accountability, transparency and efficiency.

Research on MIS holds a relatively peripheral position in the study of Information and Communications Technologies (ICT) in education. While many advocate MIS implementation and use in schools for purposes of enhanced administrative efficiency and effectiveness (Pits, 1995; Selwood \& Visscher, 2007; Taylor, 1997), it appears as if the number of studies that examine the realization of such potential is rather scarce. Studies that explore the effects of MIS use in schools present a dichotomous and imbalanced portrayal; while the majority of studies celebrate the ways in which MIS enhance leadership, management and parental involvement (Blau \& Hameiri, 2010; Blau \& Presser, 2013; Selwood \& Drenoyianni, 1997), only a small number of studies focus on the detrimental consequences of MIS usage, mainly in relation to disempowerment and deprofessionalization of teachers (Tatnall \& Davey, 2005; Waring, Wainwright, \& Skoumpopoulou, 2011). A study by Selwyn (2011b), which interviewed British school-managers and teachers about the effects of MIS implementation, revealed an interesting finding regarding the disciplinary nature of MIS: A number of school-managers reported that the implementation of MIS had enabled them to install a discourse of accountability in their school's working culture, as 'the transparency of whole school working practices' (Selwyn, 2011b, p. 480) created a stronger sense of responsibility among teachers for their individual work. The study argues that while this state can certainly empower teachers by helping them develop a sense of ownership for their work, most school-managers were more focused on the ways in which MIS helps ensure that teachers meet their targets and deadlines most efficiently and effectively. This finding implies that MIS implementation can be considered as a 'panoptic process' (Perryman, 2006, p.1 54): Foucault (1977) describes Bentham's Panopticon as a metaphor for modern society's exercises of discipline and power. Instead of inefficient physical discipline mechanisms, institutions invest in and employ invisible disciplinary technologies that produce 'docile bodies': individuals that internalize the panoptic gaze and engage in self-surveillance (Hope, 2010). According to the study, MIS acts as a disciplinary technology which ensures that teachers internalize the panoptic gaze and act accordingly. Selwyn writes that while this state is beneficial for management, it may lead teachers to develop feelings of fault and inadequacy.

\section{Purpose of the Current Study}

As previously mentioned, the existing body of research on MIS in education mainly focuses on the technical aspects of the implementation of MIS and the positive implications it entails for administration and management. Yet there is a significant gap in the critical research that considers the social, economic, cultural, and political contexts and the detrimental consequences that the implementation of MIS may bring. Another gap in the research of MIS in education can be found in the scarcity of studies that focus on teachers' perspectives and the influences the systems have on their professional practices. It is imperative not to take this gap lightly, as teachers, whose voice is rarely heard in the existing body of research, represent the majority of MIS users.

This study intends to broaden the critical discussion on MIS in education, while considering teachers' interpretations of the neoliberal context that centers the implementation of MIS and the accountability discourse. Therefore, the study asks: What are the relationships between teachers' engagement with MIS and their sense of accountability?

In order to answer this question, two main research questions are examined: (1) to what extent do teachers perceive MIS as 'accountability tools'? (2) Following the previous subject, how do expectations of accountability when using MIS affect teachers' practice? 


\section{Method}

The study was conducted in one of Israel's top performing public high schools, located in a central urban area and one of the country's first to implement MASHOV ('feedback' in Hebrew), a prominent Israeli MIS that has been in use since 2007. The study examined responses from 17 teachers that represented $15 \%$ of the school's teaching staff. A purposive sampling strategy was used to select the participants from various disciplines, both humanities and sciences, focusing on the ones most likely to be required to fully exploit the features of MIS, including homeroom teachers, subject coordinators, and management personnel. Semi-structured interviews were conducted in order to encourage participants to share their perspectives authentically. After transcribing all interviews, a thematic analysis strategy was used to analyze the text. First, deductive and inductive methods led the search for repetitions, analogies, similarities, and differences in and between interviews. During this process, several codes were generated, such as 'accountability', 'transparency', and 'general perceptions of MIS'. Later, a thorough read of the coded text produced several themes, which were examined for their relevancy to the main research goals. Finally, two main themes were formed: (1) MIS and accountability: A matter of interpretation; (2) MIS and performativity: Pressures and misrepresentations.

\section{Findings}

\section{MIS and Accountability: A Matter of Interpretation}

The findings of this theme revealed a multifaceted portrayal of perspectives, beliefs, and understandings of the link between accountability and the use of MIS. Refuting such possible links, several teachers stated they saw no correspondence between MIS and their sense of accountability. These teachers said that in their view, the system was a 'mere technical tool', intended to enhance their professional performance with superior administrative functions. One classroom teacher said that increased demands for accountability did not accompany the implementation of MASHOV, as teachers have always been expected to exhibit a strong sense of accountability:

'...so now everything is more transparent, so what? It is not as if my work was not monitored in the old days... part of being a professional teacher is reporting what I am doing and how I am doing it...'

Other teachers stated that using the system did not make them feel more accountable for their work as they were already accountable, with one classroom teacher asserting:

'I want to be more professional and do a good job. Having to report my performance to someone else wouldn't make me a better teacher, I am supposed to look out for my students, with or without the system'.

However, a number of teachers believed that the use of MASHOV promoted and supported increased accountability, aligned to the school's principal's view that the school's MIS is a powerful tool that helps teachers develop their sense of accountability:
'As teachers, it's very easy to let certain things slide, but when you're working in a room with transpar- ent walls you behave differently. MASHOV demands you to be accountable for your actions. In the be- ginning you do things because you know that someone's watching you, but later, you internalize the su- pervision and it becomes built in, it's like brainwash...'

As this quotation implies, the principal believes that transparency and accountability are interrelated; requiring teachers to conduct their practice transparently will instill them with accountability. Several teachers identified with the principal's perspective, as one subject coordinator stated:

'Management is incapable of making sure that all of us are doing our job, but with MASHOV I know that I have to be accountable'. 
Some teachers reported that the MIS-led transparency and demands for accountability influenced their practice in various ways. One homeroom teacher praised the positive effects that transparency had on her practice:

'MASHOV requires me to be in control and know exactly what's happening with my students, I become much more professional because I know that I'm being monitored...this transparency requires me to be the best that I can be and do a better job'.

In a less positive comment, one homeroom teacher stated that the use of the system has created standardization among teachers, as working transparently upholds:

'Everyone to the same standards, you have to do things even if it's not in your nature, because otherwise you'll get reprimanded'.

Further, several teachers stated that demands for accountability led them to engage in unnecessary and time consuming actions, as one homeroom teacher asserted:

'I now do things because I know that they're (management) watching. Suppose that one of my students doesn't show up to school, I will call the parents to see what was going on and even if they didn't answer I would still update this in the system, so no one would say that I performed inappropriately...'

As the interviews proceeded, more teachers shared their critical perspectives on the discourse of accountability. According to some teachers, the system is unable to process a formative and developmental assessment and, therefore, most of their efforts are focused on reporting strictly measurable variables, such as examination grades and absence rates. As this finding implies, the need to 'report everything' [subject coordinator] prevents some teachers from engaging in truly constructive and meaningful interactions with their students.

Several teachers stated they believed that, from a managerial perspective, simply reporting various incidents through MASHOV eliminated the need for further deliberation. As one classroom teacher revealed:

'After four of my students failed in the exam, I reported it through MASHOV, and from my perspective it was a done deal... their parents could see the result and I was able to move on'.

One homeroom teacher was highly critical about this situation, stating that:

'This is absurd; management only wants everything to be documented. It's as if we are more concerned about protecting ourselves than catering to our students'.

This statement preceded another finding that related to the legislative jargon that accompanied many responses. When analyzing the data and looking for recurring words and phrases, 'evidence' and 'proof' were repeatedly mentioned by teachers when describing their engagement with the school's MIS. More than a few teachers admitted that their main motivation for documenting and reporting the different incidents was to protect themselves from criticism and allegations of unprofessionalism. Of those teachers, some focused the discussion on their accountability to management:

'I write everything in MASHOV, everything. This way, when the head teacher comes to me and asks, 'Why didn't you talk to the parents and let them know that their child was missing school?' I have a chance to defend myself and prove that I did my job correctly [homeroom teacher]'.

Other teachers were more concerned about protecting themselves from parents' accusations, as described by one of the homeroom teachers:

'One of the moms called me and complained about the fact that her daughter failed my class and that I didn't do anything to prevent it. Luckily, I referred her to MASHOV, where everything had already been documented, from the frequent absences of her daughter from most of my lessons to my many attempts throughout the year to call the mother and inform her about it...She (the mother) was then speechless! Before MASHOV I never had this kind of cold, firm evidence'. 
In conclusion, it can be asserted that teachers' responses about the link between MASHOV usage and accountability have been mixed; while some teachers believed that their sense of accountability did not derive from the usage of MIS, others believed that that MASHOV was designed to continuously develop their sense of accountability. Although several teachers considered accountability as a key element supporting their professional practices, others have focused on the negative implications, such as de-professionalization and excessive documentation of their actions.

\section{MIS and Performativity: Pressures and Misrepresentations}

As data analysis further revealed, a set of three words was repeated frequently when interviewees shared their views on transparency: 'pressure', 'fear', and 'criticism'. Some of the junior teachers reported that the requirement for performativity and transparency, alongside an underlying fear of public criticism, developed a strong sense of pressure, translating to misrepresentation and falsification of data entered into the MASHOV on three main dimensions.

First, attendance-related indicators and causes of students' absences, including illness, family function, and truancy, are mandatory inputs for homeroom teachers. At the end of each week, form leaders issue 'absence analysis' that measures the ratio of validated to invalidated absences. A few homeroom teachers reported that they were barely able to keep track of their students' absences, and needed to partially fabricate absence reasons in order to avoid criticism from management:

'It's just too much work...one week I just typed 'personal reason' for all of my absent students'. One of the homeroom teachers was highly critical of the 'absence analysis', saying that 'management only cares if everything is 'green' (validated): it doesn't matter if actually no one knows why someone was skipping school, just as long as it has been validated in MASHOV'.

According to school protocol, students are punished when their reasons for absences are unjustified and marked as truancy. As one homeroom teacher reported, he sometimes falsified the reasons for absence in the system to protect his students:

'MASHOV is too cold and alienated...one of my students broke up with her boyfriend and was too depressed to show up for a couple of days...I knew that if I had reported this incident on MASHOV as illness, no one would have said anything. She's a great kid and I didn't want her to get punished'.

Another dimension of misrepresentation appeared in performance-related inputs, as several teachers reported that the use of the system intensified their pressure to deliver strong results. Thus, in order to avoid criticism of inadequate performance, they often embellished the marks of their students:

'If a certain class has a high failure rate it's the teacher's fault. Before MASHOV I could have kept the records to myself, but today everything is transparent and immediate...I save myself the pain of being persecuted and thus give them (students) higher marks...it's funny, they say that MASHOV creates transparency but it actually creates inauthenticity [classroom teacher]'.

A third dimension of misrepresentation concerns the disciplinary incidents that teachers are obligated to report for the parents and relevant staff members to observe. As a couple of trainee teachers stated, part of their performance assessment was based on their ability to reduce such disciplinary incidents, and the less reported, the higher their assessment was. Therefore, the fear of being labeled 'unfit' led them to occasionally refrain from reporting disciplinary incidents through MASHOV, in order to potentially increase their own performance results:

'At the beginning, I used the system to report every disciplinary incident that involved my students, but then it backfired, they (supervisors) said that I did not know how to control my students...Now I don't always report when someone misbehaves so that I am not accused of being a bad and unprofessional teacher'. 
In conclusion, the findings demonstrate the increased levels of pressure and self-doubt among junior teachers as a result of continuous work with MASHOV and the demand for transparency. This has led the affected teachers to provide embellished inputs in three main areas: absence, discipline and performance -related inputs.

\section{Discussion}

The following part of the study discusses the findings in consideration of the research questions, and with respect to the participants' responses.

\section{To What Extent Do Teachers Perceive MIS as 'Accountability Tools'?}

The findings of this question convey a complex compilation of various perspectives. While a number of teachers found MIS and accountability to be interrelated, others perceived MIS as no more than a technical tool with no sub-intentions.

The school's management personnel have been using MIS as a tool to monitor students and teachers with some teachers perceiving this as a punitive tool. However, management personnel stated that one of the primary motivations for implementing MIS was to encourage teachers' own sense of accountability. In correspondence with Foucault's Panopticon metaphor (1977), instilling teachers with a sense of accountability through the use of the system is enacted in several steps. First, management creates standardization, by requiring all teachers to report their actions and activities through MASHOV. Then, knowing that management is supervising them, teachers comply with the new forced conditions. Finally, teachers innately embed the act of reporting and internalize the act of supervision in their own professional identity. Management referred to levels of effectiveness when discussing MASHOV-induced accountability: as teachers are trained to develop stronger commitment to their work at school, accountability minimizes the risk of unsatisfactory performance. Ball (2003) argues that accountability is a neoliberal mechanism, which managers install to ensure that teachers are 'personally invested in the organization' (p. 219). Clearly, this argument concurs with the findings of this research, as management personnel believed that the use of MASHOV developed a true sense of accountability in teachers.

Most teachers were also aware of the link between MASHOV and accountability. However, while management related to this link as a means of enhanced efficiency and sense of empowerment, teachers were preoccupied with the disempowering effects that MASHOV had on their professional identities and practices. This discrepancy reflects the hierarchy that the implementation of digital technology in education helps preserve (Hodas, 1996), as MIS are often implemented in a 'top-down' method that unsurprisingly conforms to managerial needs (Selwyn, 2011b; Tatnall \& Davey, 2005; Waring et al., 2011).

Several teachers reported that the transparency component of MASHOV and the pressure to account for students' performance have led to a state of 'panoptic performativity', described by Perryman (2006) as 'an inspection regime in that teachers...feel as if they are constantly being observed, and perform accordingly in order to escape the regime' (p. 155). This issue of panopticperformativity widely exists in MASHOV's documentation requirement. Alongside the implementation of MASHOV, documentation and reporting has become a dominant practice within the school. However, while complying with this newly enforced practice, teachers struggled to identify its true underlying purpose, and found themselves in a perpetual mode of inquiry and selfreflection: does documentation occur to ensure the well-being of students, or is it a defense mechanism against future allegations from management and parents, and a way to accumulate evidence and prepare for a hypothetical 'judgment day'? Several teachers believed that documentation has 
become 'ends to a means', deflecting their energy from engagement in meaningful educational processes.

Nevertheless, as the findings show, conflicting interpretations can also be found within the teaching community. As several teachers believed, accountability had little to do with MASHOV, and instead, it originated from an innate sense of professionalism. The diverse perspectives of school staff reflect the evolution of accountability in education over the past decades, as Perry and McWilliam (2007) write:

'While the origins of accountability may be located in educational practices, the concept has subsequently been changed, codified and re-invented in the modern business world.' (p.34)

The participants of this study had different beliefs concerning the definition of accountability and its assumed purposes. Whereas management defined accountability as a technical matter that ensured effectiveness across the board, teachers experienced a conflict of interest in their need to comply while still considering accountability as moral responsibility for their students. This finding relates to Olssen and Peter (2005 in Suspitsyna 2010), who distinguish between two forms of accountability: 'bureaucratic-professional accountability on the basis of experts, and consumermanagerial accountability on the basis of market standards and externally defined objectives' ( $p$. 568). While it is reasonable to assume conflicting motivations and perceptions between managers and their employees, as often observed in many other organizations, Simkins (2000) warns that schools face the risk of functioning as 'schizoid organizations' when conflict rises between the "corporatist' views of senior managers whose prime concern is with the school as a whole and its relationship with its external environment, and the more 'individualist' orientation of teachers whose prime concern is with the needs of individual pupils" (p.323).

Clearly, technology is not to blame. As we have seen, the SCOT approach accurately determines that technology is a social construct, and thus it bears occasional contradictory interpretations. The perspectives concerning MASHOV are simply a representation of some of the dominant discourses of both the Israeli society in general and the school in particular. Similarly to other education systems throughout the world, the Israeli education system has gone through considerable changes in recent decades. As previously implied, those changes can be mostly associated with global neoliberal values, seeking to revolutionize and improve public services. Nevertheless, it is imperative to be mindful of the 'goodness of fit' between those values and the true nature of the teaching profession. While schools must adapt to the outside world, they must also balance the drive for performance with their commitment to nurture moral values.

\section{How Do Expectations of Accountability When Using MIS Affect Teachers' Practice?}

Teachers are expected to document all of their classroom activities in MASHOV, including students' marks, indicators of discipline and absence, conversations with students and parents, curriculum progress, and more. However, as previously demonstrated, some teachers have struggled with the mechanistic aspect of this constant documentation.

While expectations concerning the use of MASHOV were clear, several teachers found them overbearing. They felt that the transparency element of MASHOV added to the pressure of exhibiting high levels of performativity. Feelings of inadequacy led some teachers to enter misrepresented data in MASHOV, by manipulating student-related data. According to Ball (2003), misrepresentations are a matter of normal routine in performance driven organizations such as schools, as performativity requires teachers to set their authenticity aside and focus on "producing measurable and 'improving' outputs and performances...effectivity rather than honesty is most valued in a performative regime' (pp. 222-226). 
However common they may be, misrepresentations can result in detrimental consequences on teachers' identities and their relationships with management personnel, colleagues, and students. Thus, the professional judgment and ethical practices of teachers are at risk of becoming overshadowed by the increased pressures of performativity. As the findings demonstrated, some teachers embellished student marks and attendance rates to avoid criticism; surely, those actions have little to do with educational objectives that ultimately hope to instill students with moral values. Furthermore, if students become aware of the lack of repercussions for their misbehavior or failures, there is a possibility that they will take advantage of the situation and undermine the authority of teachers, leaving the latter disempowered and deskilled.

It is important to emphasize that most of the responses regarding misrepresentations were made by junior teachers. While this does not imply that less experienced teachers are dishonest, it is possible that as they are still in the process of establishing their professional identities, they are more prone to feeling insecure and unsure about their practices. Therefore, it is essential for school management to clearly define its main objectives and requirements for the newly hired teachers. It must also provide them with a structured support system that minimizes any sense of uncertainty that could eventually translate to fear and later to inauthenticity.

\section{Limitations}

Clearly, it is difficult to generalize the conclusions of this study and apply them in other contexts outside the studied school. Although the overall design and usability of MASHOV is similar to those of other global MIS, there exists a difficulty in making appropriate comparisons, as the implementation of MIS is shaped by social, political, economic, and cultural forces that vary in different countries. Nevertheless, in accordance with Stake's views (1995 in Stark \& Torrance 2005), we assert that readers' understanding of MIS implementation in education settings will be enriched through the findings of this study. Thus 'naturalistic generalization', by which readers will naturally connect to the findings that they mostly identify with, will be possible.

\section{Conclusions}

While teachers represent the vast majority of the MIS user base, their voice is rarely heard in research projects on MIS in education. Therefore, the aim of this study was to explore and acknowledge the teachers' perspectives on MASHOV, a popular and widely-used MIS in Israeli secondary schools. The findings showed a considerable gap between ultimate managerial expectations and existing reality concerning the implementation and use of MASHOV in the school. The themes emerging from the obtained data revealed a multifaceted reality, in which the implementation and use of technology preserved power structures, while influencing many of the users' professional and personal identities.

It is recommended that future studies should place the research questions in a much broader context, by considering various environments. For example, such studies may compare the perspectives of teachers about the use of MIS in both excelling and underperforming schools, considering also the reshaping of social relations in this context. Therefore, it would be possible to examine the influence of the performativity discourse on the expectations about MIS usability more broadly and accurately. 


\section{References}

Ball, S. (2003). The teacher's soul and the terrors of performativity. Journal of Educational Policy, 18(2), 215-228.

Blau, I., \& Feldman, H. (2012). Homeroom teachers navigating effectively their classes through the MASHOV- A pedagogical management system. In Y. Eshet-Alkalai, A. Caspi, S. Eden, N. Geri, \& Y. Yair (Eds.), Learning in the technological era. Ra'anana, Israel: Open University of Israel.

Blau, I., \& Hameiri, M. (2010). Implementing technological change at schools: The impact of online communication with families on teacher interactions through learning management system. Interdisciplinary Journal of E-Learning and Learning Objects, 6, 245-247. Retrieved from http://www.ijello.org/Volume6/IJELLOv6p245-257Blau699.pdf

Blau, I., \& Presser, O. (2013). E-Leadership of school principals: Increasing school effectiveness by a school data management system. British Journal of Educational Technology, 44(6), 1000-1011.

Foucault, M. (1977). Discipline and punish: The birth of the prison. London: Allen Lane.

Griffith, A., \& André-Bechely, L. (2008). Institutional technologies. In M. DeVault (Ed.) People at work (pp. 40-56). New York: New York University Press.

Haughey, M. (2003). The impact of ICT on the work of the principal. In I. Selwood, A. Fung, A., \& C. O'Mahoney (Eds.), Management of education in the information age. London: Chapman and Hall.

Hodas, S. (1996). Technology refusal and the organizational culture of schools. In R. Kling (Ed.), Computerization and controversy: Value conflicts and social choices (pp. 197-218). San Diego: Academic Press.

Hope, A. (2010). Student resistance to the surveillance curriculum. International Studies in Sociology of Education, 20(4), 319-334.

Olssen, M., \& Peters, M. A. (2005). Neoliberalism, higher education and the knowledge economy: From the free market to knowledge capitalism. Journal of Education Policy, 20(3), 313-345.

Ozga, J. (2009). Governing education through data in England: From regulation to self-evaluation. Journal of Education Policy, 24(2), 149-162.

Perry, L. A., \& McWilliam, E. (2007). Accountability, responsibility and school leadership. Journal of Educational Enquiry, 7(1), 32-43.

Perryman, J. (2006). Panoptic performativity and school inspection regimes disciplinary mechanisms and life under special measures. Journal of Education Policy, 21(2), 147-161.

Pits, H. (1995). The school office. In B. Tagg (Ed.), Developing a whole school IT policy. London: Pitman.

Selwood, I., \& Drenoyianni, H. (1997). Administration, management and IT in education. In A. Fung, J. Visscher, B. Z. Barta, \& D. Teather (Eds.), Information technology in educational management for schools of the future. London: Chapman and Hall.

Selwood, I. \& Visscher, A. (2007). The potential of school information systems for improving school performance. In N. Soguel \& P. Jaccard (Eds.), Governance and performance of education systems. Berlin: Springer.

Selwyn, N. (2011a). Schools and schooling in the digital age: A critical analysis. London: Routledge.

Selwyn, N. (2011b). It's all about standardization - Exploring the digital (re)configuration of school management and administration. Cambridge Journal of Education, 41(4), 473-488.

Simkins, T. (2000). Education reform and managerialism: Comparing the experience of schools and colleges. Journal of Education Policy, 15(3), 317-332.

Suspitsyna, T. (2010). Accountability in American education as rhetoric and a technology of governmentality. Journal of Education Policy, 25(5), 567- 586. 
Stake, R. (1995). The art of case study research. California: SAGE Publications Ltd.

Stark, S., \& Torrance, H. (2005). Case study. In B. Somekh \& C. Lewin (Eds.), Research methods in the social science. London: SAGE Publications Ltd.

Tatnall, A., \& Davey, B. (2005). Future directions in ITEM research. In A. Tatnall, J. Osorio, \& J. Visscher (Eds.), Information technology and educational management in the knowledge society. New York: Springer.

Taylor, R. G. (1997). Potential contributions of management science to expert information systems in schools. A. Fung, J. Visscher, B. Z. Barta, \& D. Teather (Eds.), Information technology in educational management for schools of the future. London: Chapman and Hall.

Telem, M (1995). Decision support systems in service of the education system. In D. Hen (Ed.), Education towards the $21^{\text {st }}$ century. Tel Aviv: Ramot Press.

Visscher, J., Wild, P., \& Fung, A. (2001). Information technology in educational management. The Netherlands: Kluwer Academic Publishers.

Waring, T., Wainwright, D., \& Skoumpopoulou, D. (2011). Management utopia or user dystopia? A critical analysis of university administration system. ICIS 2011 Proceedings. Paper 11. Retrieved May 10 from http://aisel.aisnet.org/icis2011/proceedings/humanbehavior/11

\section{Biography}

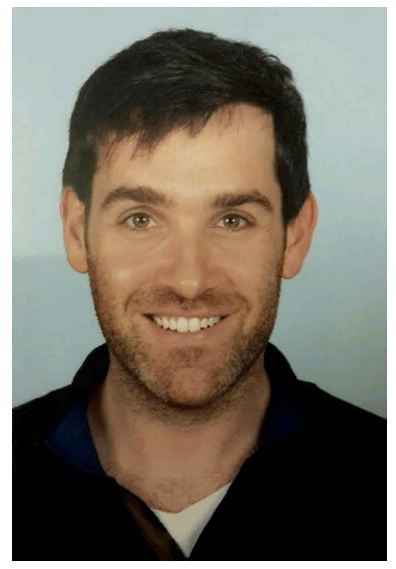

Uri Perelman is a graduate of IOE (Institute of Education) in London, UK, having completed his MA in Technology and Education. Working as a Literature teacher, Uri uses a unique and newly adopted method of Project Based Learning, which promotes and emphasizes the educated use of digital technologies in the classroom. His interests focus on the socio-political contexts of technology implementation and its use in education. The research reported in this paper is partially based on his MA dissertation. 